\title{
Strategies to Enhance Life Skills Education in High Schools: Eswatini Context
}

\author{
Racheal Mafumbate ${ }^{1 *} \quad$ Zanele Simelane $^{2}$ \\ 1.University of Eswatini, Department of Educational Foundations and Management, Faculty of Education. \\ 2.Nsongweni High School, Eswatini
}

\begin{abstract}
The youth in Eswatini are facing several challenges which require a comprehensive, coordinated, and multisectorial response from the government and other relevant stakeholders. Cases of high school dropout rate, HIV/AIDS prevalence, violence, drug and substance abuse, and poor academic performance, are on the rise in the country. The learners' behaviours indicate inadequate knowledge of Life Skills Education which are indicators of ineffective implementation of the programme in high schools in Eswatini. This study was therefore, conducted to ascertain strategies which can be used to enhance Life Skills Education in high schools in the Shiselweni region of Eswatini. The study adopted a qualitative research approach using a multiple case study design. The theory which informed the study is the Targeting Life Skills Model by Hendricks (1998). The target population were Life Skills Education teachers and high school learners in the Shiselweni region. A purposive sample of three high schools in which the Life Skills Education programme was piloted in the region was selected. Data were collected using semi-structured interview guide and focus group discussion guide. Interviews were conducted with a total of nine learners whereas focus group discussions were carried out with twenty Life Skills Education teachers. Data was analysed using Thematic analysis. Findings revealed several factors as vital in enhancing Life Skills Education in high schools. These are: 1) making Life Skills Education examinable, 2) collaboration with parents and other schools, and 3) provision of needed resources such as adequate training of teachers, providing incentives, and provision of a variety of instructional materials. It was recommended that Life Skills Education should be considered as an examinable subject. Furthermore, teachers should be adequately trained on Life Skills Education and be provided with needed resources. Last but not least, parents should be sensitized on the importance of Life Skills Education.
\end{abstract}

Keywords: Life skills, Life Skills Education, challenges, implementation.

DOI: $10.7176 / \mathrm{JEP} / 10-12-20$

Publication date: April $30^{\text {th }} 2019$

\section{Introduction}

Adolescents are considered to be productive members of society due to their intellectual capacity, unfortunately most of them are unable to utilize their potential to the fullest due to inappropriate environment (Arparna \& Raakhee, 2011). They are always engaging in antisocial activities such as drug and substance abuse, violence, early pregnancies, crime, and general indiscipline, which deteriorate their physical and intellectual capabilities (UNESCO, 2012). WHO (2011) observes that young people are not sufficiently equipped with Life Skills Education to help them deal with increased demand and stress they experience. Parental influence in moulding moral and social values and the traditional school curriculum are seemingly becoming increasingly incapable of equipping young people with the skills needed to face real life (Wairimu, 2015). To make the life of adolescents valuable, and to convert them to individuals with high potential, there is need for the educational system to be reformed, giving due importance to Life Skills Education.

Life Skills Education was conceptualized as one of the means to improve the well-being of the youth by empowering them to deal with the many challenges of life (UNESCO, 2011). It aims at providing a deeper understanding of life skills especially in the case of adolescents. Life Skills Education also strengthens the ability of an individual to meet the needs and demands of the present society and deal with issues in a manner to get desired behaviour practical (Prajapati, Sharma \& Sharma, 2017). The acquisition of new skills expands the individual's capacity to understand the world around them and develop the tools required to live a productive and fulfilling life (Meier \& Naude, 2017). A child is said to have attained optimal development if he/she has the ability to acquire culturally relevant skills and behaviours which allow him/her to function effectively in his/her current context as well as to adapt successfully when the context changes (Early Childhood Counts, 2009).

Life skills are those abilities that enable an individual to deal effectively with the demands and challenges of everyday life, like coping with difficulties they face in their personal, emotional and social development (Chaudhary \& Mehta, 2012). They are psychosocial competencies that enable an individual to develop adaptive and positive behaviour (KICD, 2009). Furthermore, life skills provide a link between motivating factors and behaviour by translating knowledge of what to do and the attitudes and values of what one should do, into abilities for how to do (Scripture Union of Uganda, 2014). The major set of life skills include: decision-making, problemsolving, creative thinking, critical thinking, effective communication, interpersonal relationship skills, self- 
awareness, empathy, coping with emotions, and coping with stress (WHO, 2011).

\section{Statement of the problem}

Research has shown that the implementation of Life Skills Education has faced numerous challenges (Kaimuri, 2008). Ever since the subject was introduced in the education curriculum globally, it seems not to have instilled the practical knowledge it was intended to. A comprehensive Life Skills Education syllabus was produced, and workshops and seminars were organized for head teachers and teachers (Wairimu, 2015). Despite these efforts, there seems to be a problem because Life Skills Education has not been reflected as much in learners' behaviour. Cases of high school dropout rate, HIV/AIDS prevalence, and poor academic performance, for instance, are on the rise in Eswatini (Ngcamphalala, 2015). It is on this basis that this paper focuses on ascertaining strategies which can be employed in order to enhance Life Skills Education in high schools.

\section{Review of related literature}

Rungu (2008) established that training of teachers is essential for proper implementation of Life Skills Education in schools. The study revealed that properly-trained personnel is a must if any programme is to be effective in achieving its intended objectives. This is also consistent with the study by Ithangi (2007) who asserted that teachers in Kamukunji complained that they had not been sufficiently trained to handle the Life Skills Education syllabus. Kaimuri (2008) observes that training of teachers on Life Skills Education in Kenya has been taking place at a very slow pace. Monyangi (2010) also supported the above findings and recommended in-service training courses for all teachers involved in teaching Life Skills Education so as to enhance teaching of the subject in schools. Meanwhile, Guajardo (2011) argued that teachers facing heavy workloads need sufficient motivational support in order to sustain their effort and professional conduct on the job.

Furthermore, Okech (2015) advised that schools need to be equipped with enough textbooks and other supplementary resources for effective teaching of Life Skills Education. Okech (2015) further recommended other supplementary resources like audio-visuals and board-games as they would make the teaching more interactive and interesting to learners. UNICEF-ESARO (2012) on the other hand, advocated for use of participatory methodologies in order to enhance Life Skills Education. These refer to child-centred teaching-learning processes which may include the following techniques: games, posters, role play and drama, case studies, brainstorming, debates, panel discussions, group discussions, story-telling, songs, field trips, research, and interviews. This kind of learning was seen as integral for life skills development as it gives the learner an opportunity to be involved in the learning process.

Meanwhile, Kitimo (2014) had a feeling that making Life Skills Education examinable in national examinations would make learners understand its importance. This finding concurs with (Rooth, 2015) who observed that Life Skills Education was not taken seriously by teachers because it was not an examinable subject. Sharing similar sentiments was Wairimu (2015) who noted that due to the non-examinable status of Life Skills Education, little effort was invested in teaching and learning of the subject. Wairimu (2015) therefore, appealed to the Ministry of Education and Training in Kenya to make the subject examinable in national examinations. It was further established that parental involvement was another strategy that could enhance the teaching and learning of Life Skills Education. The observation was that learners experience challenges at home and within their surroundings, so parents could closely examine and rectify their children's behaviour where possible. Further suggestion was that Life Skills Education campaigns be held so as to sensitize and create more awareness to communities.

\section{Theoretical framework}

The study was guided by the Targeting Life Skills Model by Hendricks (1998), also known as the 4-H Model or Framework. Youth development professionals are concerned with helping young people become competent in life skills that will prepare them for transition to adulthood. The Model focuses on developing skills that are healthy and productive for both young people and their communities. Hendricks (1998) opines that skills are learned in sequential steps related to the age and stage of development of the young person. The Targeting Life Skills Model categorizes essential life skills into four main categories which are: Head, Heart, Health, and Hands. Head includes knowledge, reasoning, and creativity competencies; Heart includes personal or social competencies; Health includes health or physical competencies; whereas Hands include vocational or citizenship competencies.

The Targeting Life Skills Model (4-H Model) by Hendricks (1998) is more appropriate for this study because there is a complementary signage between the Model and the Life Skills programme offered in high schools. The Life Skills programme aims at developing learners holistically in relation to cognitive development (HEAD), psychomotor skill development (HAND), and social skills development (HEALTH \& HEART). The programme aims at empowering learners with skills such as critical and creative thinking (HEAD), interpersonal relationship skills (HEART), entrepreneurial skills (HAND), and self-awareness (HEALTH). 


\section{Research Methodology}

The study adopted a qualitative research approach using a multiple case study design to ascertain strategies which can be employed to enhance Life Skills Education in high schools in the Shiselweni region of Eswatini. The multiple case study design allows multiple methods of data collection to be used to investigate a research problem (Choongwa, 2018). The target population for this study was fifty (50) Life Skills Education teachers and four hundred (400) high school learners in the Shiselweni region. These comprised of Life Skills Education teachers and learners from the five (5) high schools where the Life Skills Education programme was piloted in the Shiselweni region. Life Skills Education teachers from these schools were targeted since they facilitate the teaching and learning process of the Life Skills Education syllabus in their respective schools, thus knowledgeable on issues of life skills. Learners were targeted because they are beneficiaries of the Life Skills Education curriculum. A purposive sample of three (3) high schools in the Shiselweni region was selected.

Data were collected using semi-structured interview guide and focus group discussion guide. Interviews were conducted with three (3) learners per school whereas focus group discussions were carried out with a total of twenty Life Skills Education teachers. Trustworthiness was ensured by paying attention to 1) credibility, 2) transferability, 3) conformability, and 4) dependability. Data were analysed using thematic analysis by Braun and Clarke (2006). This is also called thematic networks techniques (Choongwa, 2018). Joanna and Jill (2011) argue that thematic analysis is an interpretive process, where data is systematically searched to identify patterns within data in order to provide illuminating description of the phenomenon.

\section{Findings of the study}

The study established that Life Skills Education is viewed as an imperative subject in high schools by both teachers and learners since it empowers young people with unique tools for making informed decisions. Furthermore, participants revealed that there are numerous challenges hindering effective implementation of Life Skills Education in high schools. Findings however, pointed out to several strategies which can be employed in order to enhance Life Skills Education in high schools. The following are themes that emerged during the focus group discussions: 1) making the subject examinable, 2) collaboration with parents and other schools, and 3) provision of needed resources such as adequate training of teachers, providing incentives, and providing a variety of instructional material.

\subsection{Theme 1: Life Skills Education should be made examinable}

Findings revealed that the non-examinable status of Life Skills Education negatively influences learners' attitudes towards the subject. It also influences teachers to utilize time allocated for Life Skills Education for syllabus coverage of other subjects. Participants believed that learners can start taking the subject seriously if they know they will be examined on it at the end. Otherwise for now, they view the Life Skills Education sessions as leisure activity and thus do not take them seriously.

The following are voices of participants supporting the above statements:

The Ministry of Education and Training should make Life Skills Education examinable as the nonexaminable nature of the subject makes learners and the other teachers attach very little importance to it (Participant \# 1, a 42 year old male teacher from Case A).

Life Skills Education should be assessed so that both learners and teachers can take it seriously. Government should also make Life Skills Education a core subject; it should not be optional (Participant \# 4, a 35 year old male teacher from Case A).

\subsection{Theme 2: Need for collaboration with parents and other schools}

Findings of the study also pointed out that development of Life Skills Education should not be left to the school alone. Parents should also try to make time for their children so that they are not left to face the challenges of life on their own or with the help of grandparents or elderly people only. Parents have a major responsibility in developing personal and ethical values in their children, and they are concerned with the information that their children are getting at school. If parents are informed and sensitized about what their children are taught, they would encourage them when they get home. The involvement of parents in Life Skills Education will complement the efforts of the teachers and this in turn will promote overall development of the child.

The following are voices of participants drawn from a focus group discussion:

The parents have to work hand-in-hand with the teachers. The teaching of life skills should start with the parent at home. The teacher should find that the base or foundation has already been laid and should just add to what the parent has taught the child (Participant \# 5, a 26 year old male teacher from Case A). If parents would cooperate with the teachers, it would be easy to know even the problems each child is facing so as to provide the necessary assistance as teachers. At times we find that a learner with problems just drops out of school without us knowing of his or her challenges yet we would be giving the necessary support, had we known (Participant \# 2, a 48 year old female teacher from Case C). 
Furthermore, participants cited collaboration with other schools as vital in enhancing Life Skills Education. They were positive that creating opportunities for learners to interact with peers from other schools can foster development of life skills. The following is a quote from one participant in a focus group discussion in support of the above statements:

Teachers should let students interact with learners from other schools and share ideas. For example, for a school in the rural area, we can organize one from the urban area to come and share ideas even on challenges they face and how they overcome them (Participant \# 1, a 44 year old female teacher from Case C).

\subsection{Theme 3: Providing a variety of instructional material and needed resources}

From the study, it came evident that schools lack variety in as far as instructional materials are concerned. Participants strongly believed that provision of a variety of technological tools was cardinal in promoting Life Skills Education in schools and also making its implementation a success. They were of the view that lack of such materials negatively impacts on the learner's ability to acquire life skills.

The following is a statement from one participant in support of the above view:

One of the measures that should be put in place to enhance Life Skills Education in schools is to ensure that there is provision of relevant materials and instructional equipment. This could be in a form of audio/visual materials and equipment such as movies, films, and projectors, to name a few, (Participant \#5, a 26 year old male teacher from Case A).

Findings also indicated that provision of the necessary teaching and learning resources would make Life Skills Education appealing and interesting to learners thus promoting inculcation of life skills. These include adequate training of teachers and also providing incentives. Findings revealed that properly-trained personnel is a must if any programme is to be effective in achieving its intended objectives. Participants in all three Cases echoed the same sentiments on the importance of training Life Skills Education teachers in order to enhance Life Skills Education in schools. They argued that training is crucial for teachers as Life Skills Education is taught differently from other subjects in that it is particularly concerned with teaching of values, and values are not learnt as other curriculum subjects. Participants further recommended that they should be trained for a longer period than the usual duration of about 3 days.

The following are voices from participants in a focus group discussion: Teachers need to be trained fully for them to be ready to teach the subject, even if it calls for a full year's training. This will help them know the right approaches in teaching Life Skills Education and also for the subject to be taken seriously (Participant \# 1, a 42 year old male teacher from Case A)

Teachers need to be trained themselves before going to teach the learners. They need to have current and relevant information for them to teach Life Skills Education effectively. As teachers, we ought to have accurate information, not junk. We need training now and again so that we can have up-to-date information. We should avoid a situation whereby the children are more knowledgeable than us or rather have more current information when we have outdated one. Such will be embarrassing (Participant \# 6 , a 45 year old female teacher from Case C).

Adequate training of teachers was therefore, seen as essential for enhancing Life Skills Education in schools. Participants also emphasized the need for in-service training so that they can acquire adequate and relevant information. They will be equipped even on the right approaches for imparting life skills.

Furthermore, investigation on the challenges teachers face in enhancing Life Skills Education in schools revealed that lack of motivation was one of them. The study noted that participants were disappointed in that they are not remunerated for teaching Life Skills Education yet it is an extra work-load to them. They had a feeling that government should recognize their effort by at least giving them incentives. These may be in a form of extra pay or allowances just like it is the case with sports teachers. From the study, it emerged that well-motivated, competent and committed teachers provide one of the surest routes to improved learning achievement.

The following are quotes from participants regarding provision of incentives:

Remunerate the Life Skills Education teachers so as to motivate them, for example, the allowances given to sports teachers should be given to them as well because the teaching of Life Skills Education is an extra load as they have the other subjects to teach (Participant \# 1, a 42 year old male teacher from Case A).

Government should provide incentives so as to motivate the teachers. As it is, we find ourselves demotivated especially because the learners do not even like the subject; most of them have no passion for it (Participant \# 2, a 40 year old male teacher from Case C).

\section{Discussion of findings}

Findings revealed that the non-examinable process for Life Skills Education negatively influences learners' attitudes towards the subject. Participants echoed that teachers used time allocated for Life Skills Education for 
covering or revising other subjects. Hence the feeling was that the Ministry of Education and Training should make the subject examinable so that it can be taken seriously by both teachers and learners. Participants were positive that teachers and learners could take the subject seriously if they know it would be examined. Findings in this study are in agreement with findings by Kitimo (2014) who established that if Life Skills Education could be examined in national examinations, learners might understand its importance.

These findings are in line with Wairimu (2015) who also established that the National Examinations Council of Kenya in collaboration with the Ministry of Education and Training in that country should ensure that Life Skills Education is examined in the national examinations. Participants felt that little effort was invested in the subject by both teachers and learners, due to its non-examinable status. The implication is that there is need for the Ministry of Education and training to make Life Skills Education examinable in national examinations. This will help develop a positive attitude among learners and teachers towards the subject and thereafter, they will give it more attention. The study also established that provision of the necessary teaching and learning resources would make Life Skills Education appealing and interesting to learners thus promoting inculcation of life skills. Participants felt adequate training of teachers, provision of incentives, and also providing a variety of instructional material such as audio-visual materials and equipment, would enhance appreciation of the subject among teachers, learners and other stakeholders.

Findings revealed that for any programme to be effective in achieving its intended objectives, properly-trained personnel is a must. The study also established that in-service training of teachers was necessary as it would help teachers acquire adequate and relevant information. Participants were of the view that such training would help equip them with the right approaches for imparting life skills to learners. This is consistent with findings by Monyangi (2010) who also recommended in-service courses for all teachers involved in teaching Life Skills Education. Similar sentiments were shared by Kimbui (2011) who observed that lack of professional updating negatively affects the implementation of Life Skills Education.

Furthermore, findings indicated that Life Skills Education teachers lack motivation to teach the subject because there are no rewards. The study further established that giving incentives to Life Skills Education teachers will positively influence teaching of the subject. Sharing the same view is Guajardo (2011) who opined that in as much as pay on its own does not increase teacher motivation, pecuniary motives however, are likely to be dominant among teachers where pay and material benefits are too low for individual and household survival needs to be met. Guajardo (2011) argued that teachers facing heavy workloads need sufficient motivational support in order to sustain their effort and professional conduct on the job.

Findings in this study pointed out that provision of a variety of instructional material or technological tools is cardinal in promoting Life Skills Education and for its successful implementation. Participants were positive that instructional materials will improve the quality of teaching because these would facilitate hands on learning as teachers teach. Moreover, Life Skills Education resources will help provide sufficient information to teachers as well as expose them to a variety of teaching-learning methodologies to enable them to comfortably impart this new subject in interesting and creative ways. Findings indicated that lack of such materials inhibits Life Skills Education and negatively impacts on the learner's ability to acquire life skills.

These findings are in line with Okech (2015) who advised that schools need to be equipped with enough textbooks and other supplementary resources for effective teaching of Life Skills Education. Other supplementary resources like audio-visuals and board-games were recommended as they will make the teaching more interactive and interesting to learners. The implication is that school administrators, in collaboration with the Ministry of Education and Training, should ensure that relevant teaching and learning resources are available in schools. Without adequate teaching and learning materials, learners are unable to acquire life skills at a greater extent, to enable them to function and overcome the challenges of life.

It also emerged that, development of life skills should not be left to the school alone. Parents should also try to make time for their children so that they are not left to face the challenges of life on their own. Parents have a major role to play in facilitating the development of their children's life skills and should refrain from entirely depending on teachers for their children's life skills development. Participants further opined that it is the parents' duty to develop personal and ethical values in their children. Moreover, findings indicated that parents ought to encourage their children to put into practice what they are taught at school. Participants believed that parental involvement in Life Skills Education will complement the efforts of the teachers and eventually promote overall development of the child.

Sharing the same sentiments is Wairimu (2015) who asserts that parents should be involved in the implementation of Life Skills Education since learners experience challenges at home and within their surroundings. Given this situation, parents may closely examine and rectify their children's behaviour where possible. This implies that there is need for intensifying parental participation or involvement in the teaching and learning of Life Skills Education. Other than parental involvement, collaboration with other schools was also viewed as one of the strategies for enhancing Life Skills Education in schools. Participants were positive that creating opportunities for learners to interact with peers from other schools would foster development of life skills. 
Through this practice, learners will be able to share ideas on how to cope when faced with various challenges.

\section{Conclusion}

Based on the findings above, it is evident that ever since the Life Skills Education programme was introduced, teachers have faced numerous challenges which have continued hindering the implementation. Some of the crucial factors hampering the teaching and learning of Life Skills Education include inadequate training of teachers, negative attitudes of learners, lack of motivation for teachers, and increased work load for Life Skills Education teachers. The study established various strategies that could be employed to enhance Life Skills Education in high schools which include: 1) making the subject examinable, 2) collaboration with parents and other schools, and 3) providing the needed resources such as adequate training of teachers, providing incentives, and providing a variety of instructional material.

\section{Recommendations}

In light of the findings above, the following recommendations are made to policy makers and relevant stakeholders, regarding strategies that can be used to enhance Life Skills Education in high schools:

1. The Ministry of Education and Training should ensure that teachers already in the field attend in-service training to improve their knowledge and skills towards Life Skills Education.

2. There is also need for teachers' refresher courses on Life Skills Education which will help the teachers develop appropriate knowledge, attitudes and competencies in handling learners' life skills development.

3. The Ministry of Education and Training should ensure that Life Skills Education is examined in national examinations so as to change the attitude developed by learners and teachers towards the subject.

4. The Ministry of Education in conjunction with head teachers should also ensure provision of the necessary teaching and learning resources to make the subject appealing and interesting to learners.

5. There is also need to sensitize parents on the importance of Life Skills Education so that they may understand their role in enhancing life skills development in their children.

\section{References}

Aparna, N. \& Raakhee. A.S. (2011). Life Skills Education for Adolescents: Relevance and Importance. GESJ: Education Science and Psychology 2 (19).

Braun, V. \& Clarke, V. (2006). Using thematic analysis in psychology. Qualitative Research in Psychology, (3) $77-101$.

Chaudhary, S. \& Mehta, B. (012). A Life Skills Intervention Program for Adolescents: Contextual Approach. Retrieved from http://i08.cgpublisher.com/proposals.html.

Choongwa, G.H. (2018). Fundamentals of Applied Research Methodology: A complete Guide for Scholars and Researchers in Social Sciences. Webster Print: Swaziland.

Early Childhood Counts (2009). Programming Resources for Early Childhood Care and Development, CD-ROM. The Consultative Group on ECCD. Washington D.C.: World Bank [online], available: http://www.ecdgroup.com/download/bc1pssci.pdf [accessed 20/08/2013].

Guajardo, J. (2011). Teacher Motivation: Theoretical Framework, Situation Analysis of Save the Children Offices, and Recommendation Strategies. London: Sage.

Hendricks, P. (1998). "Developing Youth Curriculum Using the Targeting Life Skills Model."Iowa State Extension.<extension.iastate.edu/4H/skls.eval.htm>

Ithangi, M. (2007). Perceptions of Teachers towards Life Skills Education on HIV/AIDS in Kamukunji Division. Unpublished MED Project, University of Nairobi, Kenya.

Joanna, S. \& Jill, F. (2011). Qualitative data analysis: the framework approach. Nurse Researcher, 18(2) 52-62.

Kaimuri, J. (2008). Factors influencing the implementation of Life Skills Education in Primary Schools of Langata Division. Unpublished MED Project, University of Nairobi, Kenya.

KICD (2009). Primary Life Skills Education Teacher's Handbook. Nairobi: Kenya Institute of Education Kenya Institute of Curriculum Development.

Kimbui, S. K. (2011). Implementation of Life Skills Education in Public Primary Schools in Ruiru District. Unpublished Thesis. Kenyatta University, Kenya.

Kitimo, M. (2014). Factors Influencing the Implementation of Life Skills Education in Secondary schools in Kinango District. Unpublished Thesis. Kenyatta University.

Monyangi, N.L. (2010). Teachers' Perceptions Towards Implementation of Life Skills Curriculum in Public Primary Schools in Nairobi West District, Kenya. Unpublished Thesis. University of Nairobi.

Ngcamphalala, D.C. (2015). State of the Youth Report. Mbabane: Swaziland.

Okech, D.O. (2015). Implications of Life Skills Education on Character Development in Children: A Case of Hill School. Unpublished Thesis. Africa Nazarene University, Nairobi.

Prajapati, R., Sharma, B. \& Sharma, D. (2017). Significance of Life Skills Education. Contemporary Issues in 
Education Research: (10) 1- 6.

Rooth, E. (2015). An investigation of the status and practice of Life Orientation in South African Schools in two provinces. Unpublished PhD Thesis, University of Western, Cape Town.

Rungu, K. J. (2008). Factors influencing implementation of Life Skills Education in primary schools. University of Nairobi, Kenya.

Scripture Union of Uganda (n.d.) Life Skills Training [online], available: http://suuganda.org/life-skills-training/ [accessed 09/06/2014].

UNESCO (2011). EFA Global Monitoring Report-Regional Overview: Latin America and the Caribbean.

UNESCO (2012). Youth and Skills: Putting education to work. EFA Global Monitoring Report.

UNICEF- ESARO (2005). Life Skills Based Education in South East Asia, A Regional Overview prepared for: The South Asia Life Skills Based Education Forum. Kathmandu, Nepal: Formal Printing Press.

Wairimu, K. H. (2015). Factors Influencing Implementation of Life Skills Education in Primary Schools in Starehe Sub-County. Nairobi, Kenya.

WHO (2011). Preventing violence by developing life skills in children and adolescents.

Viewed 30 April 2013. 